\title{
The tranexamic acid: as chemical tourniquet during Ward-Mayo's operation
}

\author{
Sarbeswar Mandal, Sumanta Kumar Mondal*, Pragati Awasthi Pathak, Kavita Agarwal
}

Department of Obstetrics and Gynecology, IPGMER-SSKM (PG) H. Kolkata, West Bengal, India

Received: 27 November 2019

Accepted: 31 December 2019

\section{*Correspondence:}

Dr. Sumanta Kumar Mondal,

E-mail: skmondal1979@gmail.com

Copyright: (c) the author(s), publisher and licensee Medip Academy. This is an open-access article distributed under the terms of the Creative Commons Attribution Non-Commercial License, which permits unrestricted non-commercial use, distribution, and reproduction in any medium, provided the original work is properly cited.

\begin{abstract}
Background: The intra-operative blood loss which required transfusion is one of the complications in Ward-Mayo's operation. The objective of this study was to evaluate its effectiveness to minimizes hemorrhage in Ward-Mayo's operation

Methods: It is a well-designed, Clinical, interventional, prospective, randomized control trial. In the department of obstetrics and gynecology, IPGMER-SSKM (PG) H, Kolkata, West Bengal, India. More than one-year study. After ethics approval, the total number of sixty-six cases will be selected with randomization for Ward-Mayo operation and allocated into two groups operated as - Gr-A ( $\mathrm{n}=33$ cases) - by infiltrating locally tranexaminic acid, Gr-B $(n=33$ controls) - application local conventional haemostatics.

Results: The outcome informs of primary and secondary assessed, analyzed, tabulated and statistically significant showed accordingly as per graph pad software. In Table 1 and 2. The results of individual group (Gr. A and Gr. B) in forms of pry and Sec. outcomes showed that there are better outcomes in all aspects with zero mortality Tranexamic group than controls.

Conclusions: This study concluded that the Tranexamic Acid can safely and effectively used by local infiltration during Ward-Mayo' operation. Like other department, this technique can be utilized in other vaginal procedure (exEpisiotomy).
\end{abstract}

Keywords: Better outcomes, In Ward-Mayo, Local tranexamic acid infiltration

\section{INTRODUCTION}

The intra-operative blood loss which required transfusion is one of the complication in Ward-Mayo's operation, that minimized by application of different techniques like sharp dissection, electrocautery, self-retaining vaginal retractor, thrombin-soaked oxidized cellulose pack, hydro dissection and diluted vasoconstriction agents (ex:vasopressin, adrenaline), but some of them having drawbacks like their toxicities and hydro dissection having impair blood supply, tissues defences and healing. ${ }^{1-5}$ After aspiring from good results by local application of Tranexmic acid (TXA) in some other surgical units (ex: dental, ENT, orthopaedic) and also recommended by WHO (2017) [TXA should be administered at a fixed dose of $1 \mathrm{~g}$ in $10 \mathrm{ml}(100 \mathrm{mg} / \mathrm{ml})$ IV at $1 \mathrm{ml}$ per minute (i.e., administered over 10 minutes), with a second dose of $1 \mathrm{~g}$ IV if bleeding continues after 30 minutes or if bleeding restarts within 24 hours of completing the first dose in PPH], it can be used by local infiltration during Ward-Mayo's operation to reduce intra-operative blood loss and transfusion. ${ }^{6-9}$

When it is used before making incision, it acts as chemical-tourniquet not only minimized blood loss but also facilitates the identification of cleavage planes with 
easy separation and development in such age group of patients to reduce morbidity and mortality.

\section{Nowadays this agent is being used vastly in different department as below}

\section{Vaginal bleeding}

Tranexamic acid is used to treat heavy menstrual bleeding. When taken by mouth it both safely and effectively treats regularly occurring heavy menstrual bleeding and improves quality of life. Another study demonstrated that the dose does not need to be adjusted in females who are between ages 12 and 16.

\section{Child birth}

Tranexamic acid is used after delivery to reduce bleeding, often with oxytocin. Death due to postpartum bleeding was reduced in women receiving tranexamic acid.

\section{Haematology}

There is not enough evidence to support the routine use of tranexamic acid to prevent bleeding in people with blood cancers However, there are several trials that are currently assessing this use of tranexamic acid. For people with inherited bleeding disorders (e.g. von Willebrand's disease), tranexamic acid is often given It has also been recommended for people with acquired bleeding disorders (e.g., directly acting oral anticoagulants (DOACs) to treat serious bleeding, but it has some contraindications and side effects.

\section{Contraindication}

- Allergic to tranexamic acid

- History of seizures

- History of venous or arterial thromboembolism or active thromboembolic disease

- Severe kidney impairment due to accumulation of the medication, dose adjustment is required in mild or moderate kidney impairment.

\section{Common side effects include}

- $\quad$ Headache (50.4-60.4\%)

- $\quad$ Backache (20.7-31.4\%)

- Nasal sinus problem $(25.4 \%)$

- Abdominal pain (12-19.8\%)

- Diarrhea $(12.2 \%)$

- Fatigue (5.2\%)

- Anemia (5.6\%).

\section{METHODS}

The tranexamic acid is antifibrinolytic family of medication having synthetic derivatives of amino acid derivatives lysine that exert its effects through reversible blockade of lysine binding site (4-5 receptor site) on plasminogenm (PLASMIN) molecules which prevent plasmin (antiplasmin) from binding to and degradation of fibrin and preserve the framework of fibrin matrix structure, directly inhibits the activity of plasmin with weak potency and it can block the active-site of urokinase plasminogen activator with high specificity among all the serine proteases, blocks binding of $\alpha 2$-antiplasmin and inhibits inflammatory reactions and compared with epsilon-aminocaproic acid (EACA), it is more potent by a factor of 10 and the half-life in adults is approximately 2.3 hours.

It is so called chemical-tourniquet considerably decreased blood loss and help in easy creation of surgical plane when injected tranexamic acid $(2 \mathrm{gms}=20 \mathrm{ml})$ in under mentioning sites/spaces:

Both sides of paravasical spaces, cervical insertion, paracervical part of Mackenrodt and bladder pillers (may be $8 \mathrm{ml}$ in each site). ${ }^{10}$

The results of individuals groups ( $\mathrm{Gr}-\mathrm{A}$ and $\mathrm{Gr}-\mathrm{B}$ ) in forms of primary and secondary outcomes in different $\mathrm{s}$ parameters are now tabulated, analyzed statistically significant established and showed in (Tables 1, 2), diagrams and different tools by using graph pad software.

\section{Exclusion criteria}

- Known hypersensitivity

- Subarachnoid haemorrhage

- Renal failure

- Haematuria.

\section{RESULTS}

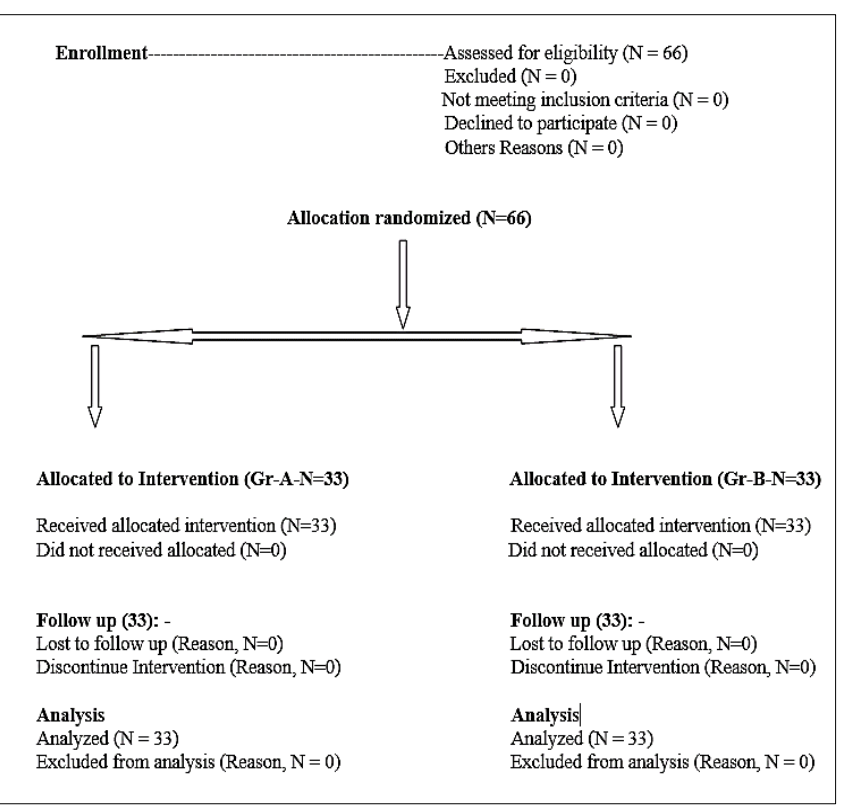

Figure 1: Consolidated standards of reporting trails (consort) statement. 
Table 1: primary outcomes in the forms of following parameters of this study with conclusive statistically significant (p-value) accordingly.

\begin{tabular}{|llll|}
\hline Indicators & GR-A $(\mathbf{N}=\mathbf{3 3})$ & GR-B $(\mathbf{N}=\mathbf{3 3})$ & Conclusion \\
\hline Organ damage/failure & & $8 / 25$ & $\mathrm{p}=0.0268$ \\
\hline Ureter & $1 / 32$ & $12 / 21$ (stained urine) & $\mathrm{p}=0.0169$ \\
\hline Bladder & $3 / 30$ (stained urine) & $9 / 24$ & $\mathrm{p}=0.0129$ \\
\hline G.I.T. & $1 / 32$ & $11 / 22$ & $\mathrm{p}=0.0326$ \\
\hline Vessels & $3 / 30$ & & $\mathrm{p}<0.0001$ \\
\hline Blood loss & & $* 50, * 8, * 45.96$ & $\mathrm{p}=0.0378$ \\
\hline Volume drain (operation) & $* 20, * 5, * 28.72$. & $* 300, * 50, * 287.23$ & $\mathrm{p}<0.0001$ \\
\hline Drains $(48$ hours) & $* 150, * 50,287.23$ & $2, .05, .28$ & $\mathrm{p}<0.0001$ \\
\hline Hb Drop & $1, .05, .28$ & $800,50,287.23$ & $\mathrm{p}<0.0001$ \\
\hline Mops wt (wet-dry) & $400,50,287.23$ & $2.7, .05, .28727$ & \\
\hline Pcv drop & $1.8, .01, .0574$ & & $\mathrm{p}=0.0169$ \\
\hline Transfusion required & & $12 / 21(03$ units $)$ & $\mathrm{p}<0.0001$ \\
\hline Blood & $03 / 30(01$ unit $)$ & $33 / 0(\geq 1$ unit $)$ & $\mathrm{p}<0.0001$ \\
\hline F.F.P. & $00 / 33$ & $33 / 00(\geq 1$ unit $)$ & $\mathrm{p}<0.0001$ \\
\hline Platelets & $00 / 33$ & $27 / 05$ & $\mathrm{p}<0.0001$ \\
\hline Volume expanders & $03 / 30$ & $25 / 08(\mathrm{BP}$ decreased $)$ & $\mathrm{p}=0.0005$ \\
\hline Hypotension/hypertension & $05 / 28$ (BP increased) & $\mathrm{p}=0.0048$ \\
\hline Chest discomfort & $2 / 31$ & $15 / 18$ & $\mathrm{Not}$ applicable \\
\hline I.T.U/C.C.U. care & $00 / 33$ & $08 / 25$ & \\
\hline Death & NIL & & \\
\hline
\end{tabular}

FET: Fisher's Exert Test, UTT: Unpaired-t-test, Mean SEM \pm SD.

Table 2: Secondary outcomes, in the forms of following parameters of this study with conclusive statistically significant (p-value) accordingly.

\begin{tabular}{|c|c|c|c|c|}
\hline Indicators & $\begin{array}{l}\text { Group A }(\mathbf{n}=33) \\
\text { (cases) }\end{array}$ & $\begin{array}{l}\text { Group B }(\mathrm{n}=33) \\
\text { (controls) }\end{array}$ & p-value & Reference \\
\hline Operation time & $50.5 \pm 8.7 \mathrm{mins}$ & $76.3 \pm 9.4 \mathrm{mins}$ & $\mathrm{p}<0.0001$ & Unpaired-t-test \\
\hline Angle hematoma & $\begin{array}{l}\text { BUAL-Site-3 } \\
\text { Incision-4 }\end{array}$ & $\begin{array}{l}\text { Clamps/tourniquet site-15 } \\
\text { Incision-10 }\end{array}$ & $\mathrm{p}=0.0010$ & Fisher's Exert Test \\
\hline Stitch line hematoma & 10 & 36 & $\mathrm{p}<0.0001$ & Fisher's Exert Test \\
\hline Approximation failure & 11 & 34 & $\mathrm{p}=0.0002$ & Fisher's Exert Test \\
\hline Stitch whole injury & 14 & 30 & $\mathrm{p}=0.0099$ & Fisher's Exert Test \\
\hline Cut through and avulsion & 7 & 24 & $\mathrm{p}=0.0007$ & Fisher's Exert Test \\
\hline Mobilization time & $8,2,11.49$ & $18,4,22.98$ & $\mathrm{p}=0.0288$ & UTT-TTP \\
\hline Oral feeding time & $10,2,11.49$ & $20,4,22.98$ & $\mathrm{p}=0.0288$ & UTT-TTP \\
\hline Post-operative pain & $\begin{array}{l}\text { Less and good } \\
\text { satisfaction }(30 / 3)\end{array}$ & $\begin{array}{l}\text { More and poor } \\
\text { satisfaction }(0 / 33)\end{array}$ & $\mathrm{p}<0.0001$ & Fisher's Exert Test \\
\hline $\begin{array}{l}\text { Analgesic needs } \\
\text { and satisfaction }\end{array}$ & $12,2,11.49$ & $24,4,22.49$ & $\mathrm{p}=0.0093$ & UTT-TTP \\
\hline Febrile complication & 5 & 20 & $\mathrm{p}=0.0022$ & Fisher's Exert Test \\
\hline $\begin{array}{l}\text { Wound healing, } \\
\text { infection, pain and } \\
\text { hardness, complication }\end{array}$ & 6 & 23 & $\mathrm{p}=0.0010$ & Fisher's Exert Test \\
\hline Re- admission & 2 & 5 & NA & NA \\
\hline Hospital stay & $7,1,5.74$ & $14,2,11.49$ & $\mathrm{P}=0.0026$ & UTT-TTP \\
\hline $\begin{array}{l}\text { Costs (sutures and } \\
\text { medications) }\end{array}$ & $\begin{array}{l}\leq 3 \text { sutures/case and } \\
\text { less medications }\end{array}$ & $\begin{array}{l}\geq 5 \text { sutures/case and } \\
\text { more medications }\end{array}$ & NA & NA \\
\hline
\end{tabular}

FET: Fisher's Exert Test, UTT: Unpaired-t-test, Mean SEM \pm SD. 
The results of individuals groups ( $\mathrm{Gr}-\mathrm{A}$ and $\mathrm{Gr}-\mathrm{B})$ in forms of primary and secondary outcomes in different $s$ parameters are now tabulated, analyzed statistically significant established and showed in tables (Tables 1,2), diagrams and different tools by using graph pad software (Figure 1).

Allocation done sequentially numbered opaque sealed enveloped (SNOSE), where sequence generated computerized random number generator and envelopes size, shape, weight confirmed equally having - Code-GrA (cases), Code-Gr-B (controls).

Aluminums foil inside envelopes was used to render envelops impermeable to light.

Envelops number in advanced, opened sequentially only after participants' name and other details written on appropriate envelops.

Envelops contains carbon papers which essential for audit trial.

Must registry entry of patients 'profile.

The primary outcomes in forms of organs failure or damages on ureters, bladder, GIT and vessels are statistically less in our study group compared to controls ( $p=0.0129, p=0.0326)$, estimated blood loss $(E B L)$ (measured in form of drains, mops, Hb drops and PCV drops) are statistically less in our study group compared to controls ( $\mathrm{p}<0.0001, \mathrm{p}=0.0378$ ), required transfusion in form of blood, FFP, platelets, volume expanders are statistically less in our study group compared to controls ( $\mathrm{p}<0.0001, \mathrm{p}=0.0169)$, cardiovascular and other complications (hypotension/ hypertension, chest discomfort, I.T.U/ C.C.U care) are statistically less in our study group compared to controls $(\mathrm{p}<0.0001, \mathrm{p}=$ 0.0048 ) without any mortality as per description from Table 1.

The secondary outcomes in forms of operation time $(\mathrm{p}<$ $0.0001)$, angle haematoma $(\mathrm{p}=0.0010)$, stitch line haematoma ( $\mathrm{p}<0.0001)$, approximation failure $(\mathrm{p}=$ $0.0002)$, Stitch whole injury $(\mathrm{p}=0.0099)$, cut through and avulsion $(\mathrm{p}=0.0007)$, mobilisation time $(\mathrm{p}=$ $0.0288)$, oral feeding time $(\mathrm{p}=0.0288)$, post-operative pain $(\mathrm{p}<0.0001)$, analgesic needs and satisfaction $(\mathrm{p}=$ 0.0093), Febrile complication ( $\mathrm{p}=0.0022)$, wound healing, infection, pain and hardness, complication ( $\mathrm{p}=$ $0.0010)$, re-admission, hospital stay $(\mathrm{p}=0.0026)$ are statistically better in our study group compared to controls as per derived from (Table 2).

\section{DISCUSSION}

A systematic review (Cochrane reviewed) of randomized trials assessing the effects of tranexamic acid in patients undergoing surgery found that it reduced blood loss and the risk of receiving a blood trans-fusion along the risk of death (Ker 2012; Ker 2013). The CRASH-2 trial that involved 20,211 bleeding trauma patients found that early administration of tranexamic acid reduced the risk of death with no increase in thromoembolic effects. In the United States, FDA approved Tranexamic acid is used in dentistry in the form of a 5\% mouth rinse after extractions or surgery in patients with prolonged bleeding time; e.g., from acquired or inherited disorders. It has also been recommended for people with acquired bleeding disorders (e.g., directly acting oral anticoagulants (DOACs)) to treat serious bleeding. The use of tranexamic acid, applied directly to the area that is bleeding or taken by mouth, appears useful to treat nose bleeding compared to packing the nose with cotton pled gets alone. Tranexamic acid is used to treat heavy menstrual bleeding. When taken by mouth it both safely and effectively treats regularly occurring heavy menstrual bleeding and improves quality of life. Tranexamic acid is used after delivery to reduce bleeding and death due to postpartum bleeding. In our study the primary outcomes informs of statistically significant less blood loss [volume drain (operation), drains (48 hours), Hb drop, mops wt (wet-dry), pcv drop], less transfusion required (blood, F.F.P., platelets, volume expanders), less chest discomfort, BP complications, organs damages and ITU/CCU care. The secondary outcomes statistically significant less in forms of operation time, angle hematoma, stitch line hematoma, approximation failure, stitch whole injury, cut through and avulsion, mobilization time, oral feeding time, post-operative pain analgesic needs and satisfaction, febrile complication, wounds (healing, infection, pain and hardness, complication), re-admission, hospital stay costs (sutures and medications).

Limitation of this study was on average; an additional 10 minutes of operating time was required for the uterine depletion procedure when combined with either an abdominal myomectomy.

The learning curve for ligation of the uterine arteries by the abdominal route might be longer for inexperienced surgeons.

If this uterine depletion procedure is to be routinely performed in myomectomy in the future, more surgical training will be required. It is single centre study, with small sample size required long follow-up required especially reproductive life in future not properly evaluated. Needs multicentre randomized controlled trials (RCT).

\section{CONCLUSION}

This step should be adopted as prophylactic ,integral and debut step by the surgeons specially in developing World where inadequate blood transfusion as this is a preliminarily more effective step for reducing blood loss, advocated and recommended its routine use as safe and convenient to other haemostatic methods not only in 
this operation and must be incorporated in G\&O training for enriched and taught surgeons other vaginal surgery.

\section{ACKNOWLEDGMENTS}

Authors would like to thank all the patients recruited in the study and all the members of the department of obstetrics and gynecology and thankful to Institutional Ethics Committee, IPGMER-SSKMH, Kolkata, India.

\section{Funding: No funding sources}

Conflict of interest: None declared

Ethical approval: The study was approved by the Institutional Ethics Committee

\section{REFERENCES}

1. Cunningham BJ, Donnelly M, Bourke A, Murphy JE. Cardiovascular and metabolic effects of cervical Epinephrine infiltration. Obstet Gynecol. 1985;66:93.

2. Jullian TM, Johnson GW, Gosewehk JA, O'Connell BJ. Vasopression as chemical tourniquet during vaginal surgery. J Gynecol Surg. 1993;9:161.

3. Lazar MR, Kriger HA. Blood loss in vaginal surgery: a comparative study. Obstet Gynecol. 1959;13:707.

4. England GT, Randall HW, Graves WL. Impairment of tissues defense by vasoconstrictor in vaginal hysterectomy. Obstet Gynecol. 1983;61:271.
5. Evans DG, Miles AA, Niven JSF. The enhancement of bacterial infection by Adrenaline. $\mathrm{Br} \mathrm{J}$ Exp Pathol. 1948;29:20.

6. Hamid RS, Fathi WK, Al Wattar WT. The effect of Tranexamic acid on post-surgical bleeding following removal of impacted wisdom teeth in healthy individual. Ra Fidain Dent J. 2008;8(2):225-30.

7. Roberts I. Tranexamic acid in trauma: how should we use it? J Thromb Haemost. 2015;13 Suppl 1:S195-9.

8. Eleje GV, Eke AC, Igberase GO, Igwegbe AO, Eleje LI. Cochrane Database of systemic review. 2015;5:Art:CD011000.

9. Chen CC, Wang CC, Wang CP, Lin TH, Lin WD, Liu SA. Prospective, randomized, controlled trial of tranexamic acid in patients who undergo head and neck procedures. Otolaryngol Head Neck Surg. 2008;138(6):762-7.

10. Dunn CJ, Goa KL. Tranexamic acid: a review of its use in surgery and other indications. Drugs. 1999;57(6):1005-32.

Cite this article as: Mandal S, Mondal SK, Pathak PA, Agarwal K. The tranexamic acid: as chemical tourniquet during Ward-Mayo's operation. Int J Reprod Contracept Obstet Gynecol 2020;9:696-700. 